Proc. 13th Econophysics Colloquium (EC) and 9th Symposium of Physics in Economy and Social Sciences (FENS), 2017

\title{
Determinants of Mass Poverty in the Contemporary Global Economy
}

\author{
A. JAKIMOWICZ ${ }^{a, *}$ AND A.A. BAKLARZ ${ }^{b}$ \\ ${ }^{a}$ Institute for Market, Consumption and Business Cycles Research - National Research Institute, \\ Al. Jerozolimskie 87, PL-02001 Warsaw, Poland \\ ${ }^{b}$ Faculty of Management, University of Warsaw, Szturmowa 1/3, PL-02678 Warsaw, Poland
}

\begin{abstract}
The concept of mass poverty was defined by Galbraith in late 1970s and it applies to societies with agriculture as the dominant branch of the economy. This paper examines the importance of this phenomenon and factors affecting it in the contemporary world. There are a growing number of studies supporting the claim that the method of electricity consumption is a key factor of economic growth which makes it possible to escape mass poverty. Moreover, in order to solve the problem, it is necessary to determine access to capital in such countries and societies, understood as M2 aggregate. In this manner, the problem at hand is reduced to determination of the relationships between the following variables: percentage of rural population, rules of managing electrical energy and M2 aggregate. These findings were used to formulate three study hypotheses. According to the first hypothesis, the effect of the electricity use method on M2 varies from one country to another, with several identifiable patterns. According to the second hypothesis, the process of leaving the mass poverty sphere follows either the Bose-Einstein distribution or the Boltzmann distribution. The third hypothesis indicates that effects of efforts aimed at eliminating mass poverty in certain conditions are not permanent. Verification of these three hypotheses indicates the adequacy of the theory of mass poverty in the contemporary world.
\end{abstract}

DOI: 10.12693 /APhysPolA.133.1388

PACS/topics: 89.65.Gh, 03.75.Nt

\section{Introduction}

The issue of poverty and the responsibility of wealthy countries to tackle the problem remains the subject of a lively debate among the top economists in the world [16]. On multiple occasions, their proposed solutions inspired international organisations to boost economic growth in poor countries [7]. To initiate a discussion on mass poverty, it is necessary to offer a proper clarification of the ambiguous term. This paper uses the definition provided by Galbraith who contends that mass poverty is characteristic of agricultural societies [8]. Galbraith made his observations in years 1961-1963 during his tenure as United States Ambassador to India. According to his definition, the percentage of rural population can be regarded as an indicator of mass poverty in a given country. Obviously, it is a simplified view and there are other indicators referring to the number of people living in deep poverty, such as the poverty gap ratio at $\$ 1.25$ a day (PPP) (\%) [9]. However, it seems that in terms of economy, most mass poverty-stricken countries remain stuck on agriculture, which most of their inhabitants rely on to earn their livelihood.

\section{Power consumption and M2 money supply as the crucial factors for determining the level of mass poverty}

In the words of the Russian economist Kondratieff, economic growth is driven by waves of technological ad-

\footnotetext{
* corresponding author
}

vancements [10]. The current wave is linked to the development of information and communication technologies [11]. The International Energy Agency reports that global energy consumption doubled in years 1973-2014 (from 4,661 Mtoe to 9,425 Mtoe) [12]. Simultaneously, the consumption of electrical energy nearly quadrupled, which implicates in a significant shift in the manner of consuming energy. Since late 1970s, causal relationships between energy consumption and economic growth in different countries have been researched in the framework of the Granger causality and the Toda-Yamamoto causality. Although the relationship between the electrical energy and the GDP has been proven, there is yet no satisfactory confirmation of the relationship between total energy consumption and the GDP [13]. As the importance of energy continues to gain recognition, some new theoretical models consider energy consumption in the Cobb-Douglas economic growth models [14]. This approach substantiates the claim that one of the key factors in assuring economic growth, and thus overcoming mass poverty, is a transformation of the economy to increase the efficiency of electrical energy consumption.

Mass poverty is related to a deficiency in financial resources which prevents people from satisfying even the most basic human needs. In poor societies, any improvement of living conditions requires cash, which allows people to buy necessary goods. Therefore, the availability of currency (understood as the real M2 aggregate) serves as an indicator of the society's wealth. In this case, the GDP fails as an indicator of mass poverty as it includes revenue from capital, which usually belongs to the wealthier members of society, thus hampering the estimation of the part of currency in circulation owned by the poor. 


\section{Classification of countries by the civilisation of life indicator}

In order to classify countries by their manner of electrical energy spending, researchers created an indicator of the civilisation of life, measuring the energy intensity of an employed person $\left(E_{C}\right)$ :

$$
\begin{aligned}
& E_{\mathrm{C} \text { country, year }} \\
& =\frac{\text { electrical energy consumption }_{\text {country, year }}}{\text { working population }_{\text {country, year }}} .
\end{aligned}
$$

The research was based on data from years 1990-2011, available at The World Bank website in the World Development Indicators folder [15]. Two parameters were observed over time: electrical energy consumption in $\mathrm{kWh}$ and working population in the country. Energy intensity was calculated for all countries in the database. Moreover, average energy intensity was calculated on the basis of data aggregated for the whole world. The results were converted with the use of a two-state function

$$
\begin{aligned}
& f_{\text {country, year }+1}= \\
& \left\{\begin{array}{cc}
1 \text { if } \frac{E_{\mathrm{C} \text { country, year } 11}-E_{\mathrm{C} \text { country, year }}}{E_{\text {Ccountry,year }}}> \\
-1 \text { if } \frac{E_{\mathrm{C} \text { country, year+1 } 1-E_{\mathrm{C} \text { country, year }}}}{E_{\mathrm{C} \text { country, year }}} \leq \\
\frac{E_{\mathrm{C} \text { world, year }+1-E_{\mathrm{C} \text { world, year }}}}{E_{\mathrm{C} \text { world, year }}} .
\end{array}\right.
\end{aligned}
$$

Then, an all-year total ( $\left.\Sigma f_{\text {country }}\right)$ was calculated for each country. Eventually, a table with a single index including the values from -22 to 20 was established for each country. The distribution of values of the civilisation of life indicator is presented in Fig. 1. The peak created for the value of -15 refers to the so-called third world countries, which developed slower than the world economy in the period under examination. It should be also observed that the distribution of the proposed index does not correspond to the Gaussian curve.

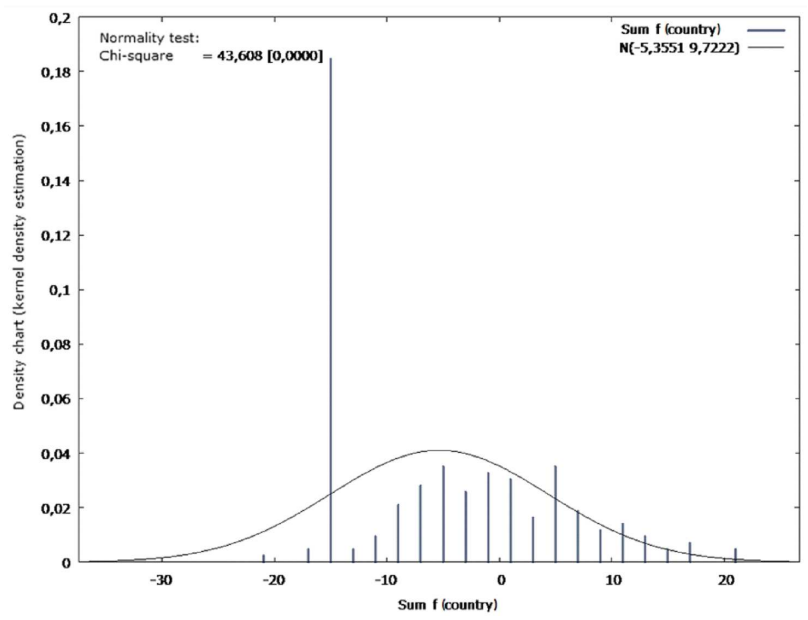

Fig. 1. Distribution of data for the civilisation of life indicator.
A simplified classifier with values ranging from 0 to 3 was created for the established matrix. The classifier 0 group included 82 countries with the lowest $\Sigma f_{\text {country }}$ (e.g. Afghanistan, Tajikistan, Chad, Grenada, Rwanda, Samoa), the classifier 1 group included 27 countries (e.g. Benin, Colombia, Congo (Dem. Rep.), Haiti, Korea (Rep.), the Kyrgyz Republic, Mongolia, Montenegro, Romania, Zambia), the classifier 2 group included 83 countries, and the classifier 3 group - 22 countries (e.g. China, India, Indonesia, Portugal). Furthermore, the civilisation of life indicator as at the beginning of the study period (year 1990) was calculated for each country. The third quartile of all values equaled $6.535 \mathrm{kWh} / \mathrm{employed}$ person. The countries whose index fell into the fourth quartile were labelled 1 as developed in terms of civilisation, whereas the remaining countries were labelled 0 .

Thereafter, the countries were divided into groups taking both classifiers into account. The spatial distribution of countries, classified based on their civilisation of life indicator, is presented in Fig. 2. A two-character label indicates a country developed in terms of civilisation, and the following character represents the dynamics of the increase in electrical energy consumption. However, note that group 10 includes only 3 countries (New Zealand, Tajikistan, Uzbekistan), and group 13 - just a single country (Iceland).

\section{Relationship between M2 monetary aggregate and electrical energy consumption in different groups of countries}

The civilisation of life indicator enables to classify the world economy into country groups by assessing how their electrical energy efficiency impacts on their real M2 monetary aggregate. Almost all groups demonstrate a statistically relevant, linear relationship between the increase in currency accumulation and the manner of electrical energy use. Group 10 is the only exception, probably due to the lack of data on the supply of M2

TABLE I

Relationship between the M2 monetary aggregate and electrical energy consumption in different groups of countries.

\begin{tabular}{l|c|c|c}
\hline \hline Groups & $\begin{array}{c}\text { Angular } \\
\text { coefficient } \\
\text { (for electrical } \\
\text { energy) }\end{array}$ & Probability & $R^{2}$ \\
\hline 0 & 0.344033 & $3.18 \times 10^{-11}$ & 0.894448 \\
\hline 1 & 1.70399 & $8.95 \times 10^{-8}$ & 0.768021 \\
\hline 2 & 1.46535 & $9.48 \times 10^{-13}$ & 0.925601 \\
\hline 10 (incomplete data) & 1.92741 & $1.30 \times 10^{-21}$ & 0.990307 \\
\hline 11 & 1.83025 & 0.1434 & 0.103924 \\
\hline 12 & 10.5722 & $1.94 \times 10^{-13}$ & 0.936477 \\
\hline 13 (one country) & 1.21067 & $5.73 \times 10^{-10}$ & 0.859311
\end{tabular}


money for Uzbekistan in years 1990-1997 and for Tajikistan. Table I shows that an improvement in electrical energy efficiency prompts an increase in the value of the indicator measuring how efficiently the energy is used to generate wealth (correlated with money supply - M2 aggregate). Group 12 countries, thanks to their efficient electrical energy use, generate as much as $\$ 15$ from $1 \mathrm{kWh}$ (real value as in base year 2005). Group 0 countries generate only $\$ 0.3$ from $1 \mathrm{kWh}$ per hour (real value as in base year 2005).

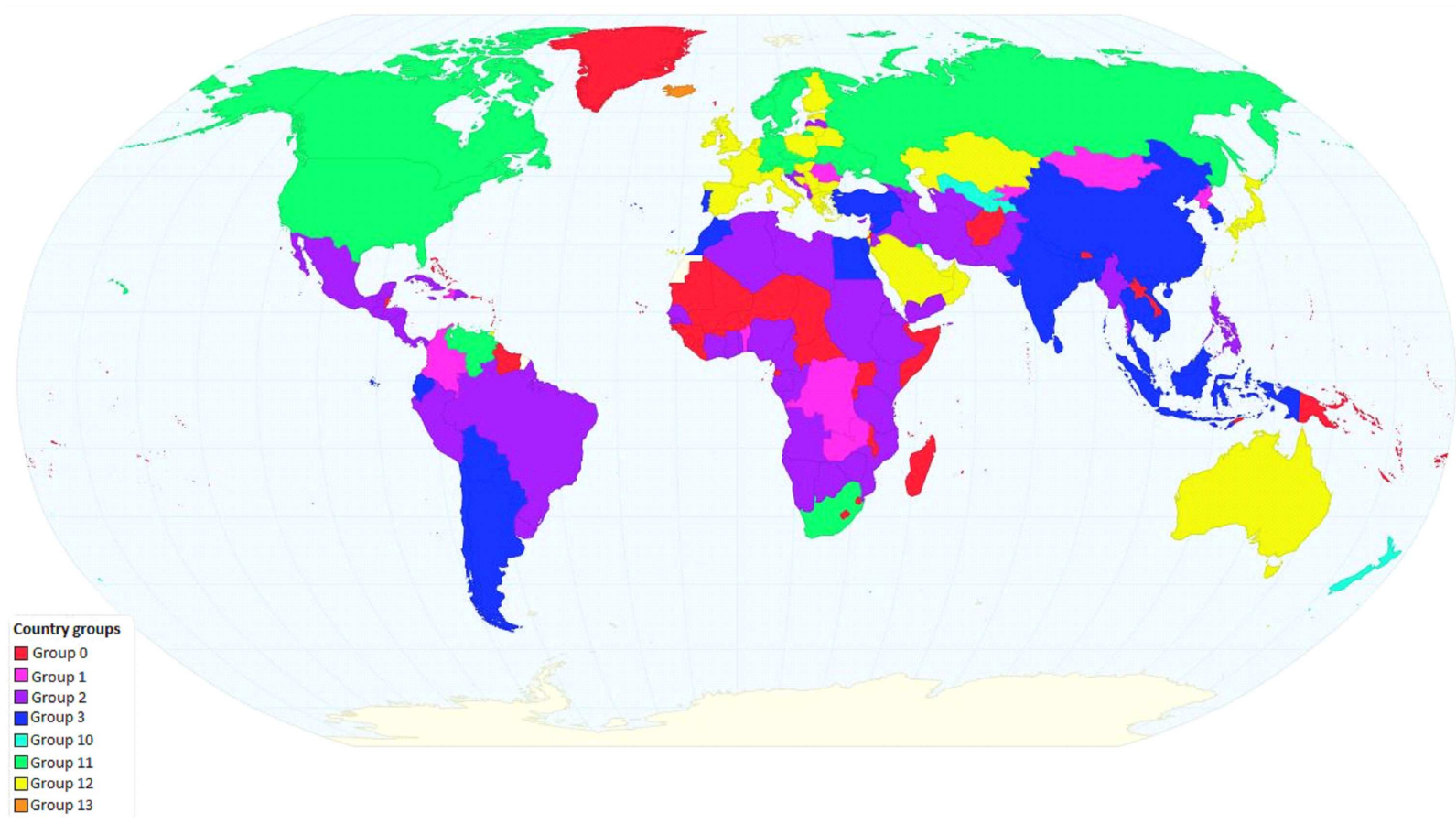

Fig. 2. Spatial distribution of countries as classified basing on their civilisation of life indicator.

\section{The paradoxes of mass poverty in selected countries}

The relationship between the percentage of rural population and GDP per capita allows some conclusions to be drawn regarding the impact of an average economic growth in a country on the speed of generating wealth among the poorest social groups (rural population). Simultaneously, it suggests that mass poverty is being combated at an increasingly fast rate. The examples of India, China, or Brazil conclusively show that the increase in GDP per capita (for a fixed money supply) is an increasing function. The relationship is non-linear. The increase seems to be a square function of time and could even be an exponential function. On the other hand, the decrease in the rural population percentage is essentially a linear function with a negative slope.

The research indicates that societies leave the mass poverty sphere following either the scheme of the BoseEinstein condensate formation or the Boltzmann distribution. The former provides a good analogue for leaving the sphere of mass poverty by individual families, while the latter can be applied for larger population groups.

The Bose-Einstein condensate is one of the states of matter [16-18]. It is formed of bosons cooled almost to absolute zero, captured in a magneto-optical trap. In this state, wave properties of atoms begin to prevail and all particles making up the condensate have the same momentum and behave as one big particle. Particles are cooled with the use of laser light, which makes it possible to get rid of high energy atoms. The latest studies showed that condensate can also exist at room temperature [19]. The phenomenon of leaving rural areas by a population occurs in a comparable manner to the formation of this condensate, where the economic equivalent of laser cooling is a decrease in family income to such a level that it turns to the state of mass poverty. The formation of the Bose-Einstein condensate is equivalent to adjustment of some members of the family to living in poverty, which - in Galbraith's opinion - is an optimum solution in a hopeless situation. However, the adjustment is never perfect and there are always people who will make an attempt to migrate from the countryside to the urban areas. They can be compared to high energy atoms escaping from the magneto-optical trap. The process of a Bose-Einstein condensate formation can be presented with the following function:

$$
N_{0} \equiv N-\bar{N}=\left[1-\left(\frac{T}{T_{c}}\right)^{3 / 2}\right] \text {, }
$$

where the physico-economic interpretation is as follows: $N_{0}$ - the number of particles making up the condensate/the number of members of the family stuck in ex- 
treme poverty in rural areas with no chances for finding a way out of the situation, $N$ - number of all particles participating in the condensate formation/number of all family members, $\bar{N}$ - number of higher energy particles evaporated from the condensate/number of family members who left the mass poverty state as a result of moving from the countryside to the city, $T$ - condensate temperature/income per family member preventing migration from the countryside to the city and resulting in adjustment to poverty, $T_{c}$ - critical temperature/income per family member, above which migration from the countryside to the city is possible.

In accordance with known geographical settlement models, migration from the countryside to towns generally follows the Bose-Einstein pattern. If a poor family has any additional income, it could encourage the first person of this family to move to urban slums. Another income boost, and the person brings one member of his or her family. Only after the whole family has moved to the slums, can they think of improving their living conditions.

Obviously, the Bose-Einstein condensation assumes that the energy provided is quantifiable. The process of generating wealth could be also described with the use of the Boltzmann distribution in the conditions of thermodynamic equilibrium, which would not require making the assumption. The Boltzmann distribution is an exponential function

$$
N_{i}=N \mathrm{e}^{-E_{i} / k T} / q,
$$

where the physico-economic interpretation is as follows: $N_{i}$ - number of physical objects in $i$-th state/number of social groups in the mass poverty state, $N$ - number of all objects/number of all social groups in a given society, $E_{i}$ - energy of $i$-th state/total utility of available basket of consumer goods in $i$-th social group, $k$ - the Boltzmann constant/marginal propensity to consume in a given society, $T$ - temperature/income per capita in a given society, $q$ - partition function/average welfare level in a given society.

Thus, the distributions are slightly different in nature. The distribution of the Bose-Einstein condensation is observed in very low energies of quantum states. Contrarily, the Boltzmann distribution offers a statistics for large numbers of particles. Therefore, the first one could offer a microeconomic perspective of a family overcoming mass poverty by moving to a city, and the other could take a macroeconomic approach, describing the process of overcoming mass poverty by a society as a whole.

Firstly, consider the rural population percentage as a function of the whole world population (Fig. 3). The function is decreasing. Therefore, one could infer that the issue of mass poverty will gradually subside over time. However, such a conclusion would be unfounded. The relationship indicates only that the urban population grows faster than the rural population.

In order to determine the type of distribution, it is required to formulate a relationship which considers the size of rural population and is not dependent on time

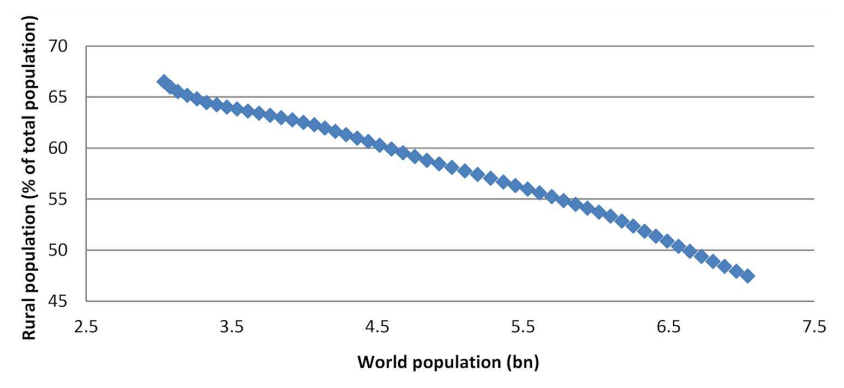

Fig. 3. Rural population percentage as a function of the whole world population (years 1960-2012).

(assuming that in less-developed economies the word rural is statistically synonymous to the word poor). GDP per capita stands for ambient temperature. The charts presented below, based on relevant time series, illustrate the relationship

$\%$ rural population (time) $=$

Function [GDP per capita (time) in current LCU].

The situation in India provides the most compelling example of mass poverty. Observations made in this country led Galbraith to introduce this term in economics. Equation (5) for this country is presented on a logarithmic scale in Fig. 4. Undoubtedly, it brings to mind the Boltzmann distribution, which intuitively seems correct: in no uncertain terms, the system (i.e. a household against the whole country) is tiny and the quanta of the money supplied are so small that they become indistinct in big statistics. Even if the similarity is less marked in the middle part, the chart still presents Pareto (power law) distribution. If GDP per capita is high, the rural population percentage (a measure of mass poverty) reaches its minimum in the equilibrium point. When GDP per capita is low, the sizeable rural population is conducive to exacerbating mass poverty.

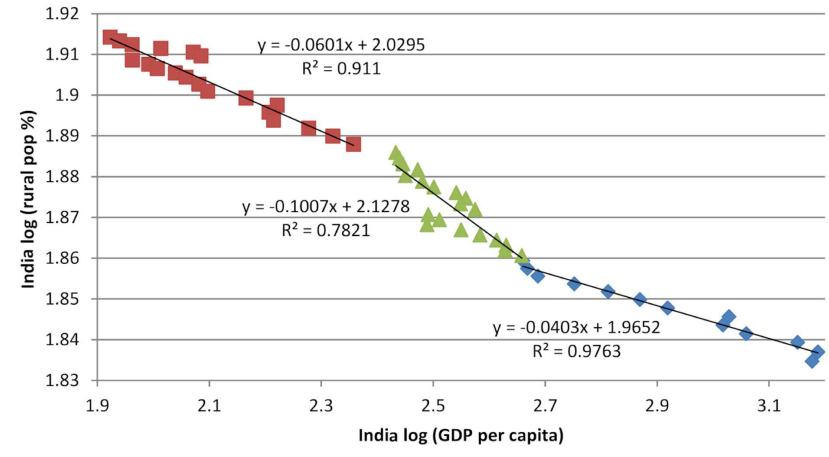

Fig. 4. Relationship of rural population percentage (time) $=$ Function [GDP per capita (time) in current LCU] on a logarithmic scale for India.

For two other poorly urbanised countries, Burundi and Bangladesh, Eq. (5) presented on a logarithmic scale looks similar (Fig. 5). The equilibrium point where mass poverty reaches its minimum level is characteristic of a given country. 


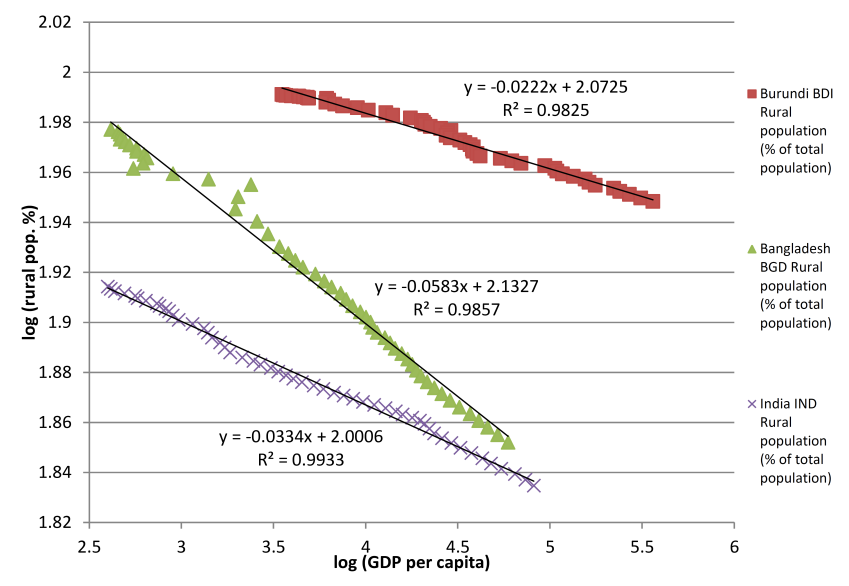

Fig. 5. Relationship of rural population percentage (time) $=$ Function [GDP per capita (time) in current LCU] on a logarithmic scale for Burundi and Bangladesh (the lowest line, describing the case of India, is added for comparison).

For some countries, the chart presents entirely different results with a reversed slope direction. Those countries include mostly former Soviet republics such as Uzbekistan, Tajikistan, and the Kyrgyz Republic (Fig. 6). In those countries, the natural state of equilibrium was artificially disturbed. When they were a part of the Soviet Union, huge construction projects of the socialist regime forced an increased migration of rural population to towns. After the dissolution of the Soviet Union, an interesting phenomenon occurred. In terms of economic growth, when the disturbance ceased, the countries returned to their former optimum. Since 1991, people who left the countryside have been going back, which indicates that the socialist methods of combating mass poverty failed to produce lasting results.

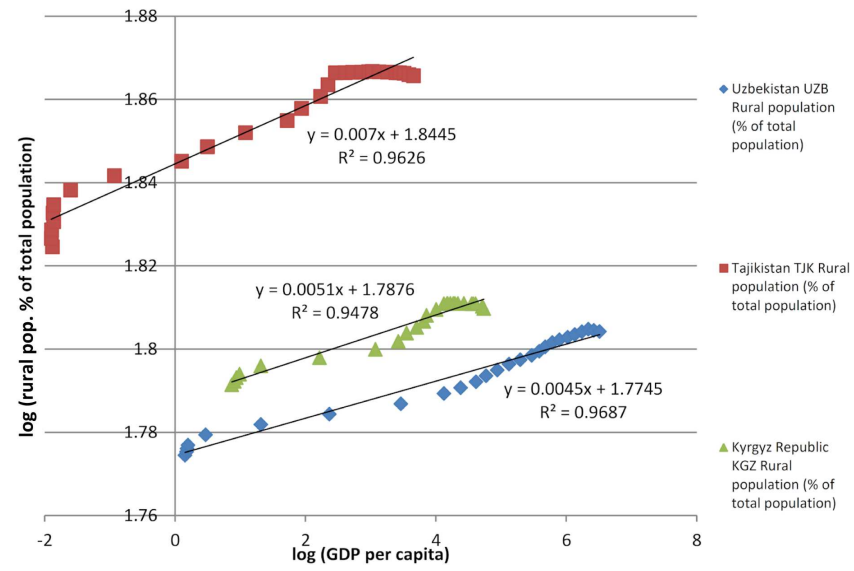

Fig. 6. Relationship of rural population percentage (time) $=$ Function [GDP per capita (time) in current LCU] on a logarithmic scale for selected former Soviet republics: Uzbekistan, Tajikistan, and the Kyrgyz Republic.

\section{Conclusions}

The civilisation of life indicator based on electrical energy consumption per employed person allows to divide the global economy into eight groups of countries. In every group, the electrical energy use has a different impact on the real M2 monetary aggregate. The process of overcoming mass poverty imitates the Bose-Einstein distribution or the Boltzmann distribution. The former takes a microeconomic approach as it describes overcoming poverty in single households, whereas the latter puts the same issue in a macroeconomic perspective encompassing the entire societies.

In some conditions, results of the fight against mass poverty are not lasting. After the factors countering poverty cease to exist, the situation spontaneously returns to the long-term equilibrium resulting from local conditions. The characteristic distribution for Uzbekistan, Tajikistan, and the Kyrgyz Republic indicates that a fusion of those economies within the Soviet Union created a new economic equilibrium with a decreased level of mass poverty. However, even though this situation was maintained for a relatively long period of time, the crucial causes of mass poverty were not eliminated, which led to a return to the original situation after 1991. It could be inferred that huge construction projects of the socialist regime served more of a political than economic purpose. They had no material impact on the historical and cultural causes of poverty, which confirms yet another conclusion drawn by Galbraith, who claimed that the equilibrium of poverty is very difficult to overcome since poverty-stricken people tolerate their situation [8]. Their ability to adapt is not a sign of a character weakness but their optimal solution. Poverty is cruel, but an endless and futile fight against poverty is even worse. The experience of the poor gathered over the centuries taught them to accept poverty as something inescapable. Therefore, their tendency to adapt becomes the best solution in a desperate situation. The only hope rests on the fact that adaptation is never perfect, even in the poorest country in the world. Some people will always try to escape mass poverty.

\section{References}

[1] D. Acemoglu, J.A. Robinson, Why Nations Fail: The Origins of Power, Prosperity, and Poverty, Crown Business, New York 2012.

[2] J.K. Galbraith, The Good Society: The Humane Agenda, Houghton Mifflin Company, Boston 1996.

[3] J.D. Sachs, The Age of Sustainable Development, Columbia University Press, New York 2015.

[4] R.J. Shiller, Finance and the Good Society, Princeton University Press, Princeton 2012.

[5] J.E. Stiglitz, Globalization and Its Discontents, W.W. Norton, New York 2002.

[6] J.E. Stiglitz, Making Globalization Work, W.W. Norton, New York 2006. 
[7] S. Chari, in: The Dictionary of Human Geography, Eds. D. Gregory, R. Johnston, G. Pratt, M.J. Watts, S. Whatmore, Wiley-Blackwell, Oxford 2009, p. 155.

[8] J.K. Galbraith, The Nature of Mass Poverty, Harvard University Press, Cambridge 1979.

[9] Poverty gap ratio at \$1.25 a day (PPP), percentage, United Nations Statistics Division.

[10] N.D. Kondratieff, Large Cycles of Conjuncture and the Theory of Foresight. Selected Works, Ekonomika Publishers, Moscow 2002 (in Russian).

[11] D. Tapscott, A.D. Williams, Wikinomics: How Mass Collaboration Changes Everything, Portfolio, New York 2006.

[12] Key World Energy Statistics 2016, International Energy Agency, Paris 2016.
[13] J.E. Payne, J. Econ. Stud. 37, 53 (2010).

[14] D.I. Stern, A. Kander, Energy J. 33, 125 (2012).

[15] The World Bank Open Data (2014).

[16] F. Dalfovo, S. Giorgini, L.P. Pitaevskii, S. Stringari, Rev. Mod. Phys. 71, 463 (1999).

[17] R. Kutner, M. Regulski, Comput. Phys. Commun. 121-122, 586 (1999).

[18] W. Ketterle, Int. J. Mod. Phys. B 16, 4537 (2002).

[19] A. Das, P. Bhattacharya, J. Heo, A. Banerjee, W. Guo, Proc. Natl. Acad. Sci. USA 110, 2735 (2013). 